DIVISION OF THE HUMANITIES AND SOCIAL SCIENCES

CALIFORNIA INSTITUTE OF TECHNOLOGY

PASADENA, CALIFORNIA 91125

CONSUMERS NETWORKS AND SEARCH EQUILIBRIA

Andrea Galeotti

Social and Information Science Laboratory, Caltech

Department of Economics, University of Essex

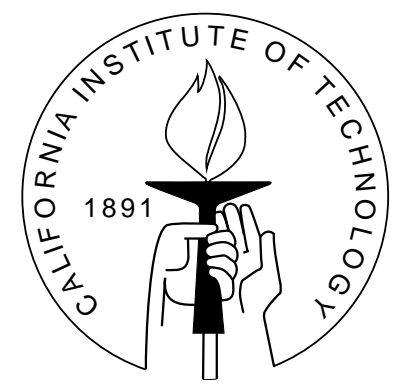

SOCIAL SCIENCE WORKING PAPER 1225

June 2005 


\title{
Consumers Networks and Search Equilibria
}

\author{
Andrea Galeotti
}

\begin{abstract}
We explore the effect of local information sharing among consumers on market functioning. Consumers are embedded in a consumers network, they may costly search non-sequentially for price quotations and the information gathered are non-excludable along direct links. We first show that when search costs are low consumers randomize between searching for one price and two price quotations (high search intensity equilibrium). Otherwise, consumers randomize between searching for one price and not searching at all (low search intensity equilibrium). In both equilibria consumers search less frequently in denser networks. The main result of the paper shows that when search costs are low the expected price and the social welfare increase, while the consumer surplus decreases, as the consumers network becomes denser. These results are reverse when search costs are high.
\end{abstract}

JEL classification numbers: D43, D83, L15

Key Words: networks, local externalities, non-sequential search. 


\title{
Consumers Network and Search Equilibria*
}

\author{
Andrea Galeotti
}

\section{Introduction}

A large body of empirical work shows that in the market a variety of informal relationships complement the price system in coordinating the interaction among buyers and sellers. For example, in marketing it is well established that consumers obtain much of their information via their social contacts (Feick and Price $(1986,1987)$ ). In relation to this, firms have increasingly recognized the need for using informal channels as a way to market their products. The practice of consumers referral is an example; ${ }^{2}$ according to the Direct Selling Association (1999), annual sales of firms that rely entirely on consumer referral grew from 13 billion to nearly 23 billion dollars between 1991 and 1998. Similarly, in the process of finding a job people heavily rely on their social contacts in order to obtain information about job opportunities (Granovetter (1974)). In medicine, and other specialized fields, professional networks shape the adoption of new technologies (Coleman 1966).

These examples share a common feature: informal relationships connecting agents transform the information that each individual privately obtains into a public good, and this affects players' incentives as well as aggregate outcomes. This fact represents the primary motivation for the development of a theory where both networks and markets mediate externalities across individuals. This paper focuses on the role of local information sharing in shaping the information available in the economy, firms' pricing behavior, social welfare and consumer surplus.

We examine a duopolistic version of Burdett and Judd (1983). On the supply side of the market there are two firms producing a homogeneous good. Firms set prices so as to maximize profits. Consumers have a common willingness to pay for the good and buy at most a single unit. The only way for a transaction to take place is that consumers have some information about prices. Consumers may search nonsequentially for price quotations and, in this case, they must pay a fixed search cost for each price quotation observed. ${ }^{3}$ In addition, consumers are embedded in a social

\footnotetext{
${ }^{*}$ I am grateful to V. Bhaskar, K. Burdett, G. Conti, S. Goyal, M. Janssen, S. Mutuswami and J.L. Moraga-Gonzalez for useful comments on earlier versions of the paper. I also thank seminar participants at University of Essex, Caltech and ESRC Research Seminars in Game Theory-UCL.

${ }^{2}$ Firms provide different sorts of benefits such as discounts to clients who bring new customers.

${ }^{3}$ Morgan and Manning (1985) show that non-sequential search is appealing when consumers find it optimal to gather price information quickly. See Janssen and Moraga-Gonzalez (2003) for a variety
} 
network and they share information freely with their direct neighbors. To maintain symmetry on the consumers side we assume that each consumer holds the same number of connections, say $k^{4}$ Once each consumer has searched, the information observed is freely provided to his direct neighbors and then transactions take place. The game is a one-shot simultaneous move game: firms set prices and consumers decide how many searches to make at the same moment. We focus on symmetric Nash equilibria. ${ }^{5}$

When the network is empty (or inactive), i.e. $k=0$, we obtain the duopolistic version of Burdett and Judd (1983). By contrast, the possibility of sharing information, i.e. $k>0$, creates information externalities across consumers. These externalities have two main effects on market competitiveness. On the one hand, for given consumers' search efforts, they increase the likelihood with which a consumer compares prices, thereby increasing firms' competition. On the other hand, they create incentives for consumers to free-ride on each other. The magnitude of these two opposite effects determines the intensity of firms' competition and therefore the overall functioning of the market. We shall show that when search costs are sufficiently low, the total information generated in the economy decreases with the connectivity of the network. In such a case, firms charge on average higher prices and consumers surplus is lower.

We start by noticing that equilibria exhibit price dispersion. ${ }^{6}$ More interestingly, for any positive degree of the network there are two types of price dispersed equilibria. The first is a high search intensity equilibrium, where consumers randomize between searching for one price and for two prices. This equilibrium exists for low search costs. The other is a low search intensity equilibrium, where consumers randomize between searching for one price and not searching at all, and it exists for moderate search costs. By contrast, when consumers do not share information (the network is empty) only the former equilibrium is strategically viable. The low search intensity equilibrium arises because even a consumer who does not search may observe two price quotations, thereby creating the tension between some consumers over which firms have monopoly power and others consumers over which firms compete for. In what follows we discuss the properties of these equilibria.

Let us first comment on the high search intensity equilibrium. Given that the degree of the network is strictly positive, this equilibrium exists for sufficiently low search costs. Further, as the degree of the network increases, the existence region of this equilibrium shrinks. The intuition is that richer network relationships reduce the marginal gains of searching twice instead of once. Thus, for sufficiently high

\footnotetext{
of oligopolistic markets where consumers search non-sequentially.

${ }^{4}$ Thus, the consumer network is a regular graph with degree $k$.

${ }^{5}$ We shall discuss strategy profiles where consumers search asymmetrically in Section 6 .

${ }^{6}$ More precisely, we show that pure strategy equilibria exist and they take the following form: consumers do not search and firms charge a sufficiently high price. In the rest of the introduction we focus the discuss on symmetric mixed strategy equilibria.
} 
search costs, consumers cannot be indifferent between the two searching alternatives. Second, we show that the equilibrium expected price is higher when the network is more dense. The intuition is based on two considerations. On the one hand, an increase in the degree of the network increases information externalities across consumers, ceteris paribus. Since consumers compare prices more often, firms' competition augments. On the other hand, consumers react to an increase in the number of connections by free-riding more on each other. This decreases information externalities. Since, for sufficiently low search costs, consumers always search, their incentives to free-ride on each others is so strong that overall firms' competition becomes less severe.

Thirdly, we show that social welfare is higher, while consumer surplus is lower, when the consumers network is more dense. The increase in social welfare is due to the strategic substitutability between searching and network degree, and to the fact that consumers are active with probability one. The former effect reduces the waste in search costs, while the second ensures that, in equilibrium, each possible transaction is indeed realized. The decrease in consumer surplus is due to the fact that firms price less aggressively when consumers hold more connections.

We finally turn to discuss the low search intensity equilibrium. This equilibrium exists for moderate search costs; further, for a given regular network, the lowest search costs for which this equilibrium exists equals the highest search cost for which the high search intensity equilibrium exists. Secondly, in sharp contrast with the previous equilibrium, an increase in the degree of the network lowers the expected equilibrium price. The intuition behind this result is that when search costs are moderate, a consumer who free-rides may not observe even one price. This has a substantial impact on the utility of the consumer and as a consequence it mitigates consumers' free-riding. As a result, richer consumers connections make consumers more likely to compare prices and this enhances firms' competition. Even if network relationships are beneficial for consumers, i.e. consumer surplus increases, they decrease social welfare. The reason is that the number of realized transactions in equilibrium decreases, an effect which offsets the saving on search costs.

The present model relates to two branches of the economic literature: the theory of networks and the search theory. We start by discussing the contribution of this paper to the theory of networks. The massive empirical documentation of network effects is behind the increasing theoretical attention of the effect of decentralized interactions on a variety of settings. ${ }^{7}$ All these studies belong to a new general class of games in which the economic activity of players is embedded in a network, which affects non trivially their incentives. In this perspective, the main contribution of the current paper is the study of the interplay between consumers information sharing

\footnotetext{
${ }^{7}$ For example, Calvo and Jackson (2004a, 2004b) study of the effect of social networks on employment and inequality. Bala and Goyal (1998) examine the effect of network on learning. Kranton and Minehart $(2000,2001)$ study buyer and seller networks. Goyal and Joshi (2003) investigate the effect of networks of collaboration in oligopoly. Ballester, Calvo and Zenou (2004) study the impact of networks in criminality activities.
} 
and market functioning. Even if our model is quite stylized, it illustrates new and important insights which arise when both networks and markets mediate externalities among individuals.

The works which come closer to mine are Bramoulle and Kranton (2003) and Goyal and Moraga-Gonzalez (2001). Bramoulle and Kranton (2004) examine a model of social learning where individuals search costly for new information and the results of their searching are non-excludable along links. While in their model the benefit each consumer obtains by searching is exogenously given, in the present paper it is the outcome of firms' competition. Goyal and Moraga-Gonzalez (2001) analyze a game where, prior competition, firms form pairwise agreement for the development of new products and they set an R\&D effort which is costly and provide a reduction of the marginal production cost. They find that the R\&D effort a firm chooses in each agreement is decreasing in the effort that the partner firm sets and that this free-riding effect may lead to inefficient market outcomes. While Goyal and MoragaGonzalez (2001) focus on the impact of network relationships on the supply side of the market, the current paper focuses on information externalities across consumers.

The consumer search literature is well established in economics. ${ }^{8}$ We have already discussed above the relation between the present paper and the model of Burdett and Judd (1983). Another paper which comes close to mine is Janssen and MoragaGonzalez (2003). They study a version of Burdett and Judd (1983) where consumers are ex-ante heterogeneous: one fraction of consumers are fully informed, while the remaining fraction must search costly to obtain price information. Increasing the fraction of fully informed consumers creates positive externalities for all consumers by boosting competitiveness and therefore lowering the expected price. The present paper provides a simple way of endogenizing information externalities across consumers using network relationships and it shows that this may create negative consumers externalities.

The rest of the paper proceeds as follows. In section 2 we define formally the model. Section 3 provides a preliminary equilibrium analysis. Section 4 and 5 characterize equilibria. Section 6 briefly discusses asymmetric equilibria and Section 7 concludes. Proofs are relegated to the appendix.

\section{The Model}

We examine a model of non-sequential search where consumers are embedded in a network of connections. On the supply side there are $N=2$ firms producing a homogeneous good at constant returns to scale. We normalize their identical unit production cost to zero, without loss of generality.

On the supply side instead, there is a finite number of consumers, which we denote

\footnotetext{
${ }^{8}$ See, among others, Anderson and Renault (2000), Bester (1994), Braverman (1980), Burdett and Coles (1997), Morgan and Manning (1985) and Stahl (1989,1996).
} 
as $m$. All consumers are identical. They want to buy a single unit of the product and their maximum willingness to pay is $\tilde{p}>0$. For a transaction to take place, consumers must observe at least one price quotation. A consumer may search simultaneously, the cost for each search being $c>0$, where $c<\tilde{p}$. In addition, the price information each consumer obtains is freely provided to his neighbors. ${ }^{9}$ For the sake of symmetry on the consumers side, I assume that the consumer network is a regular graph. Thus, the degree of the network, say $k$, may vary between 0 to $m-1$, and it represents the number of connections each consumer holds. ${ }^{10}$

We note that, when $k=0$, the model is equivalent to a duopolistic version of Burdett and Judd (1983). By contrast, as $k$ becomes positive, consumers strategically choose their search intensity, taking into account that the information their neighbors obtain is non-excludable along direct links. This clearly affects the individual incentives and, therefore, the market equilibrium outcomes. It is exactly on the interplay between the externalities produced by the consumers network and market performance that we focus in the present paper.

Firms and consumers know the architecture of the network and play a simultaneous move game. An individual firm chooses its price, taking the price choices of its rivals, as well as consumers' search behaviors as given. We denote a firm's strategy by the price distribution $F(p)$ defined on a support $\sigma$; let $p$ and $\bar{p}$ be the lowerbound and the upperbound of $\sigma$, respectively. Consumers form conjectures about the firms' price behavior and decide how many price observations to pay for. Once each consumer has searched, information is transmitted to the immediate neighbors. A strategy profile for a consumer is then a probability distribution over the set $\{0,1,2\} .{ }^{11}$ We denote as $q_{i, x}$ the probability of consumer $i$ to search $x$ time; thus a consumer's strategy is $\left\{q_{x}\right\}_{x \in\{0,1,2\}}$. We will primarily consider symmetric Nash equilibria. Asymmetric equilibria are discussed in Section 6.

\section{Preliminary Analysis}

Let us first analyze the existence and characterization of equilibria in which consumers adopt symmetric pure strategies.

Proposition 3.1. For any $k \geq 0$ and $c>0$, the only equilibria in which consumers use a symmetric pure strategy take the following form: consumers never

\footnotetext{
${ }^{9}$ It is worth noticing that we are making the following two assumptions. The first is that information transmission is perfect along direct links. The results we shall present will qualitatively hold when relaxing this assumption. The second is that we do not allow for indirect information sharing. This assumption simplifies our analysis and it allows us to study systematically the effect of an increase in information sharing on market functioning.

${ }^{10} \mathrm{~A}$ regular graph may not exist when $m$ is odd. Hence, in the paper we assume that $m$ is even.

${ }^{11}$ It is clear that the restriction of the consumers' strategy set to $\{0,1,2\}$ does not affect the equilibrium characterization. Indeed, for a consumer to search more than twice is a strictly dominated strategy.
} 
search, $q_{0}=1$, and firms charge a price $p \in[\tilde{p}-c, \tilde{p}]$.

The proof relies on two facts. One, if consumers search surely for one price quotation, they either prefer to decrease their search activity (if search cost are sufficiently high) or to search more (otherwise). Two, if consumers search surely for two price quotations, firms' competition will drive prices to marginal cost. This creates incentive for consumers to search less. This proposition pushes us towards investigating those equilibria in which consumers use a mixed strategy. The next proposition shows the possible candidates for an equilibrium.

Proposition 3.2. In any equilibrium in which consumers employ a symmetric mixed strategy firms price accordingly to an atomless price distribution, $F(p)$, defined on a convex support $\sigma$. Moreover, if $k=0$ then $q_{1}+q_{2}=1, q_{1}, q_{2} \in(0,1)$, while if $k>0$, then either $q_{1}+q_{2}=1, q_{1}, q_{2} \in(0,1)$ or $q_{0}+q_{1}=1, q_{0}, q_{1} \in(0,1)$.

There are two main observations which follow from Proposition 3.2. The first is that, despite the fact that consumers are fully homogenous, price dispersion arises in all equilibria. Since consumers search randomly, some consumers in the market are ex-post more informed than others. In line with Burdett and Judd (1983), this allows firms to extract profits by randomizing their prices. Second and more interestingly, when the network does not play any role, e.g. $k=0$, consumers must randomize between searching for one price and two prices for an equilibrium to be obtained. We refer to this as high search intensity. However, when local information sharing is taken into account, another equilibrium candidate emerges where consumers randomize between searching once and not searching at all. We call this possibility low search intensity. The intuition for this is that the presence of network relationships allow that, with some probability, even consumers who do not search at all observe both firms' prices. This creates the tension between some consumers over which firms have monopoly power and others consumers over which firms compete for.

We shall now characterize the high search intensity equilibrium and low search intensity equilibrium. For each equilibrium candidate we first characterize firms' behavior, taking consumers' strategy as exogenous. In this way, we illustrate the direct effect that networks have on the strategic way firms price. Next, we endogenize consumers' behavior in order to characterize equilibria. Finally, we analyze the impact of network density on the consumers' search intensity, firms' pricing behavior, social welfare and consumer surplus. Taken together, this analysis will clarify the effect of local information sharing on market competitiveness.

\section{High search intensity}

Suppose consumers randomize between searching once and searching twice, i.e. $q_{1}+$ $q_{2}=1, q_{1}, q_{2}>0$. The expected number of consumers who observe only the price of firm $i$, say $D_{i}$, and the expected number of fully informed consumers, say $D_{i, j}$, can 
be written as

$$
\begin{aligned}
D_{i}\left(k, q_{1}\right) & =\frac{m q_{1}^{k+1}}{2^{k+1}} \\
D_{i, j}\left(k, q_{1}\right) & =m\left(1-\frac{q_{1}^{k+1}}{2^{k}}\right)
\end{aligned}
$$

A consumer obtains only the price of firm $i$ (expression (1)) when he and all his neighborhood observe only the price of firm $i,\left(q_{1} / 2\right)^{k+1}$. Further, a consumer observes only the price of firm $j$ with the same probability that a consumer observes only the price of firm $i$, i.e. $D_{i}=D_{j}$; with the remaining probability (expression (2)), a consumer observes both prices.

Using (1) and (2), the expected profit to firm $i$ is

$$
E \pi_{i}\left(p_{i}, p_{j} ; k, q_{1}\right)=D_{i}\left(k, q_{1}\right) p_{i}+D_{i, j}\left(k, q_{1}\right) p_{i}\left[1-F\left(p_{i} ; k, q_{1}\right)\right]
$$

The next Proposition summarizes equilibrium pricing by firms, given the consumers' behavior fixed.

Proposition 4.1. Assume $q_{1}+q_{2}=1, q_{x} \in(0,1), x=1,2$. In equilibrium:

$$
F\left(p ; k, q_{1}\right)=1-\frac{q_{1}^{k+1}}{2\left(2^{k}-q_{1}^{k+1}\right)} \frac{\tilde{p}-p}{p}, \forall p \in\left[\frac{q_{1}^{k+1}}{2^{k+1}-q_{1}^{k+1}} \tilde{p}, \tilde{p}\right]
$$

Furthermore, $F\left(p ; k, q_{1}\right)$ dominates in the first order stochastic sense $F\left(p ; k+1, q_{1}\right)$, $k=0, \ldots, m-1$.

Proposition 4.1 shows that it is possible to rank the price distributions with respect to $k$ in the first-order stochastic sense: $F\left(p, k, q_{1}\right)$ first order stochastically dominates $F\left(p ; k+1, q_{1}\right)$. Therefore, as $k$ increases, firms charge on average lower prices. The intuition is as follows: when consumers hold more connections, information externalities are higher, ceteris paribus. This implies that consumers compare prices more often and thereby firms compete more. Figure 1 illustrates the equilibrium price distribution for different levels of network density.

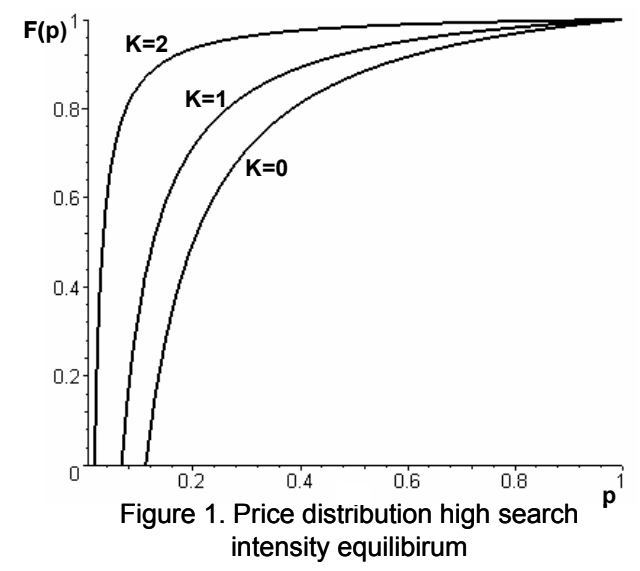


We now endogenize the consumers side. We denote as $E(p)$ the expected price obtained by randomly sampling one price from the distribution of prices $F$, while $E_{\min }(p)$ indicates the expected minimum price obtained by randomly sampling two prices. The expected utilities to a consumer from the two distinct searching alternatives are: ${ }^{12}$

$$
\begin{aligned}
& E u\left(q_{1}=1\right)=\tilde{p}-\frac{q_{1}^{k}}{2^{k}} E(p)-\left(1-\frac{q_{1}^{k}}{2^{k}}\right) E_{\min }(p)-c \\
& E u\left(q_{2}=1\right)=\tilde{p}-E_{\min }(p)-2 c
\end{aligned}
$$

In words, an arbitrary consumer $j$ who searches once, expression (4), observes only one price quotation when all his social contacts are searching once, $q_{1}^{k}$, and each of them observes the same price quotation that $j$ observes, $1 / 2^{k}$. With the remaining probability consumer $j$ is fully informed. In equilibrium a consumer should be indifferent between the two different search alternatives, i.e. $E u\left(q_{1}=1\right)=E u\left(q_{2}=1\right)$. This leads to the following equilibrium condition:

$$
\frac{q_{1}^{k}}{2^{k}}\left[E(p)-E_{\min }(p)\right]=c
$$

Each consumer trades-off the marginal cost of searching once more, $c$, with its marginal gain. The marginal gain of searching twice instead of once is the difference between buying at the expected price and at the expected minimum price, i.e. $E(p)-$ $E_{\min }(p)$, weighted for the probability with which a consumer who searches for one price will indeed observe only one price quotation, i.e. $q_{1}^{k} / 2^{k}$. When the network is empty, i.e. $k=0$, the marginal gain becomes the difference between the expected price and the expected minimum price.

The next result provides the full characterization of the high search intensity equilibrium for any given $k=0, \ldots, m-1$. Let $\bar{c}(k)=\frac{1}{2^{k}\left(2^{k+1}-2\right)}\left(\frac{2^{k+1}}{2^{k+1}-2} \ln \left(2^{k+1}-1\right)-2\right)$.

Theorem 4.1. If $k=0$ there exists a $\tilde{c}>0$ such that for any $c \in(0, \tilde{c})$ a stable high search intensity equilibrium exists where firms behave according to Proposition 4.1 and $q_{1}^{*}$ is the smallest solution of (6). If $k>0$, there exists $\bar{c}(k)<\tilde{c}$ such that for any $c \in(0, \bar{c}(k))$ a high search intensity equilibrium exists where firms behave according to Proposition 4.1 and $q_{1}^{*}$ is the unique solution of (6). Furthermore, this equilibrium is stable. ${ }^{13}$

We first elaborate on the existence condition of this equilibrium. Figure 2a below illustrates the equilibrium condition for different level of $k$. In the Figure we plot the

\footnotetext{
${ }^{12}$ More precisely expression 4 (resp. 5) indicates the expected utility to a consumer $j$ who searches for one price quotation (resp. for two price quotations), given that all other consumers are searching for one price quotation with probability $q_{1}$, and for two price quotations with the remaining probability, $1-q_{1}$.

${ }^{13}$ We refer to the notion of stability used by Fershtman and Fishman (1992).
} 
LHS of expression (6) for different level of $k$ as a function of $q_{1}$. Figure $2 \mathrm{~b}$ above illustrates that the function $\bar{c}(k)$ decreases in $k$.
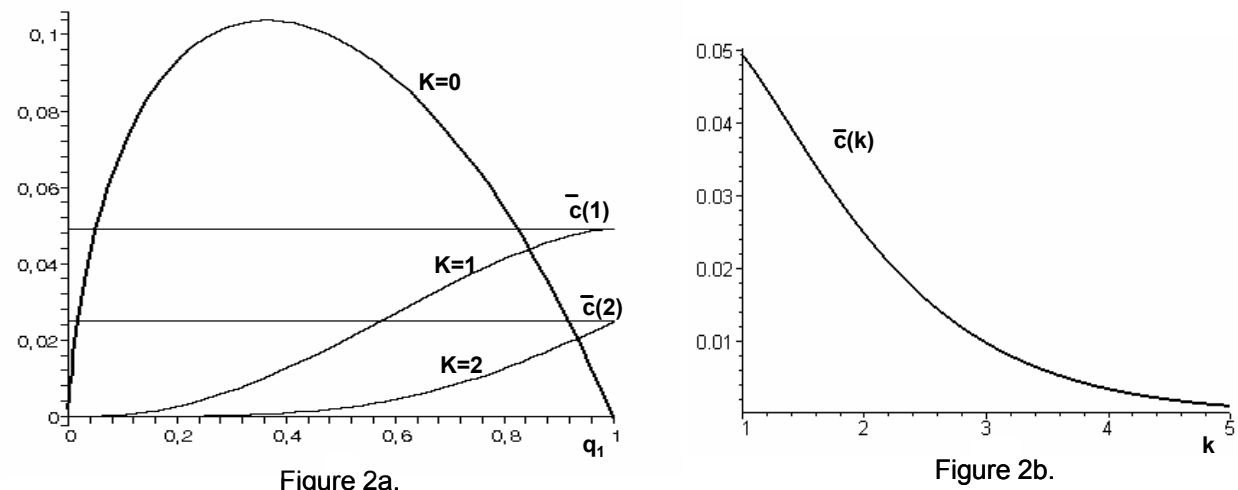

As already discussed, when $k=0$ the model is equivalent to the duopolistic version of Burdett and Judd (1983). In this case, for a given $c \in(0, \tilde{c})$ there are at most two equilibria, but only the equilibrium with high search intensity, i.e. the smallest $q_{1}$, is stable. ${ }^{14}$ Differently, when we introduce information sharing, there is a unique solution of the equilibrium condition (6), which is also stable. The first effect of information sharing is that the high search intensity equilibrium exists only when searching is relatively inexpensive. Furthermore, as $k$ increases this equilibrium exists for smaller and smaller search costs. The intuition is as follows. Network externalities reduce the marginal gains of searching twice instead of once, thereby for search costs sufficiently high a consumer cannot be indifferent between the two searching alternatives. The decrease in the marginal gains is due to two effects. The first is that richer network connections increase the probability of a consumer who searches once to compare prices, and the second is that the difference between the expected price and the expected minimum price decreases in $k$.

We now turn to analyze the effect of consumers network on search incentives, expected prices, consumer surplus and social welfare. The next proposition summarizes the findings.

Proposition 4.2. Suppose we move from $k$ to $k+1, k \in[1, \ldots, m-2]$ and assume that $c<\bar{c}(k+1)$. Then: (a) consumers search less frequently, i.e. $q_{2}$ decreases, (b) expected price increases (c) social welfare increases and (d) consumer surplus decreases.

We would like to elaborate on three aspects of Proposition 4.2. The first is that

\footnotetext{
${ }^{14}$ To see this let us assume that $c \in(0, \tilde{c})$ and let $q_{1}^{*}$ be the highest value of $q_{1}$ which solves the equilibrium condition (6). In a neighborhood to the left of $q_{1}^{*}$, say $q_{1}<q_{1}^{*}$, the marginal revenue for a consumer to search twice instead of once is higher than the respective marginal cost. Thus, consumers would search more intensively and we will move further away from equilibrium. A similar argument can be invoked for the case in which $q_{1}$ is slightly bigger than $q_{1}^{*}$.
} 
consumers search intensity decreases as the network becomes denser: an increase in the network degree leads consumers to free-ride more on each other. Secondly, this has a somewhat surprising effect on the equilibrium pricing behavior of firms: expected price is higher in settings where consumers have more connections. The intuition is the following. An increase in the degree of the consumers network induces two effects. The first is highlighted in Proposition 4.1 and it tells us that, keeping constant the consumers' behavior, an increase in the number of connections increases the expected number of fully informed consumers. The second is a free-riding effect: more connections lead players to search less intensively, thereby decreasing the expected number of fully informed consumers. When consumers search intensively, the free-riding effect offsets the former effect and as a consequence firms price less aggressively. In Figure $3 \mathrm{a}$ below we plot the probability of a consumer who searches once to be fully informed in equilibrium. In line with the intuition above, Figure 3a shows that for a given search cost the information in the market decreases when the degree of the network increases. Figure $3 \mathrm{~b}$ shows how the expected price varies with respect to the degree of the network in equilibrium.

Next, we note that consumer surplus decreases. This follows by noting that not only the expected price decreases but the same holds for the expected minimum price. Finally, we show that an increase in the degree of the network enhances social efficiency. This is due to the fact that the free-riding effect leads to saving on the total search cost, yet, since consumers search surely, each possible transaction is realized in equilibrium.
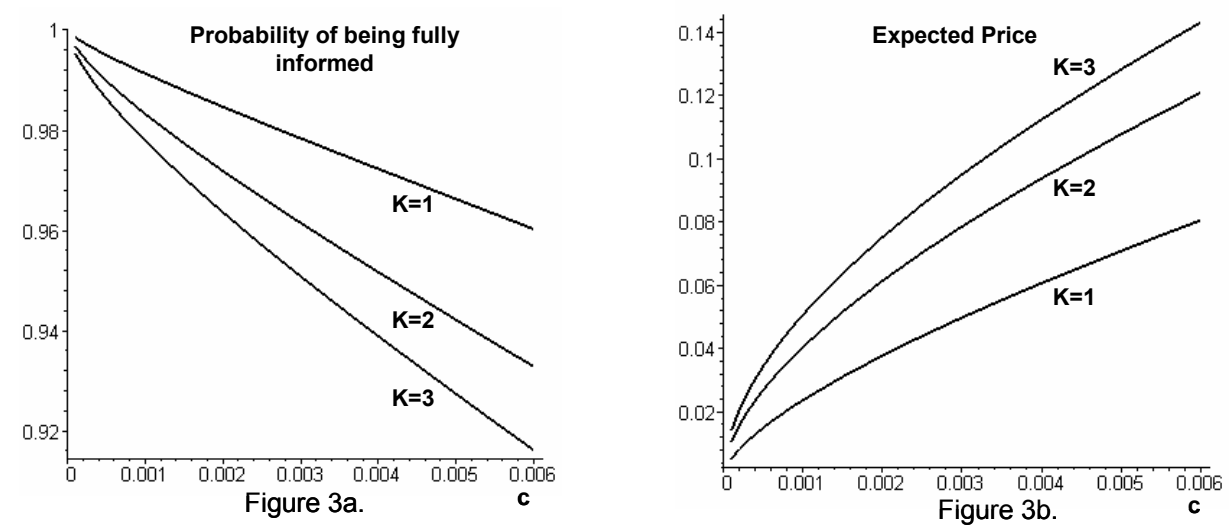

\section{Low Search Intensity}

We now analyze the case in which consumers randomize between searching once and not searching at all, i.e. $q_{0}+q_{1}=1, q_{0}, q_{1}>0$. We start by considering consumers' behavior as exogenously given. The expected fraction of consumers who observe only the price of firm $i$, say $D_{i}$, is: 


$$
\begin{aligned}
D_{i}\left(k, q_{0}\right)= & \frac{m\left(1-q_{0}\right)}{2} \sum_{x=0}^{k}\left(\begin{array}{l}
k \\
x
\end{array}\right) \frac{q_{0}^{k-x}\left(1-q_{0}\right)^{x}}{2^{x}} \\
& +m q_{0} \sum_{x=1}^{k}\left(\begin{array}{l}
k \\
x
\end{array}\right) \frac{q_{0}^{k-x}\left(1-q_{0}\right)^{x}}{2^{x}},
\end{aligned}
$$

while the expected fraction of fully informed consumers, say $D_{i, j}$, is:

$$
\begin{aligned}
D_{i, j}\left(k, q_{0}\right)= & m\left(1-q_{0}\right)\left(1-\sum_{x=0}^{k}\left(\begin{array}{l}
k \\
x
\end{array}\right) \frac{q_{0}^{k-x}\left(1-q_{0}\right)^{x}}{2^{x}}\right) \\
& +m q\left(1-q_{0}^{k}-2 \sum_{x=1}^{k}\left(\begin{array}{l}
k \\
x
\end{array}\right) \frac{q_{0}^{k-x}\left(1-q_{0}\right)^{x}}{2^{x}}\right)
\end{aligned}
$$

The interpretation of expression (7) is as follows: the first term denotes the fraction of consumers who have searched once on their own and found firm $i$, i.e. $m\left(1-q_{0}\right) / 2$, and that they have either received the same information or no information from their neighbors; the second term indicates the fraction of consumers who did not search, but that have received the price information of firm $i$ from some of their social contacts. Expression (8) as a similar interpretation. The expected profit of firm $i$ is:

$$
E \pi\left(p_{i}, p_{j} ; k, q_{0}\right)=D_{i}\left(k, q_{0}\right) p_{i}+D_{i}\left(k, q_{0}\right) p_{i}\left[1-F\left(p_{i} ; k, q_{0}\right)\right]
$$

The next Proposition summarizes the firms' price behavior in equilibrium.

Proposition 5.1. Assume $q_{0}+q_{1}=1, q_{x} \in(0,1), x=0,1$. In equilibrium:

$$
\begin{aligned}
F\left(p ; k, q_{0}\right) & =1-\frac{\left(1+q_{0}\right)^{k+1}-2^{k+1} q_{0}^{k+1}}{2\left(2^{k}\left(1+q_{0}^{k+1}\right)-\left(1+q_{0}\right)^{k+1}\right)} \frac{\tilde{p}-p}{p}, \\
\forall p & \in\left[\frac{\left(1+q_{0}\right)^{k+1}-2^{k+1} q_{0}^{k+1}}{2^{k+1}-\left(1+q_{0}\right)^{k+1}} \tilde{p}, \tilde{p}\right]
\end{aligned}
$$

Furthermore, $F\left(p ; k, q_{0}\right)$ dominates in the first order stochastic sense $F\left(p ; k+1, q_{0}\right)$.

As in the high search intensity equilibrium, an increase in the degree of the network has a direct effect on the way firms price: the higher the density of the network, the lower the expected price. This is illustrated in the Figure 4 below. 


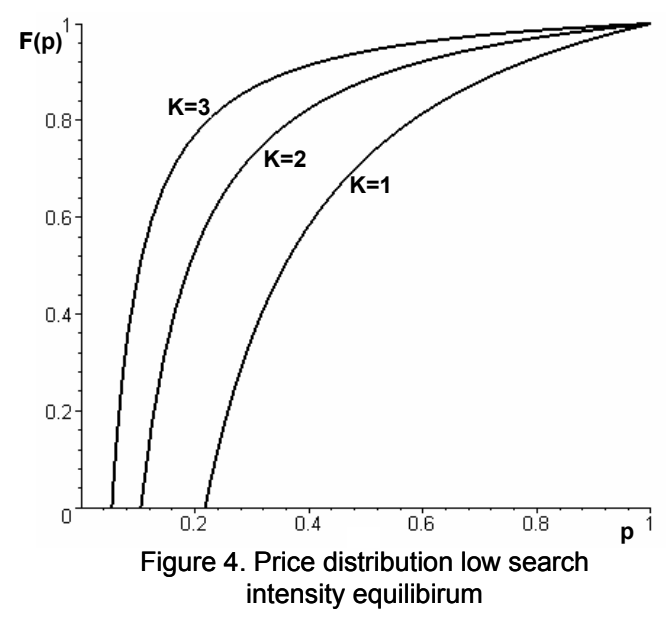

We now endogenize the consumers' search behavior. Let $\alpha\left(q_{0}, k\right)=\sum_{x=0}^{k}\left(\begin{array}{l}k \\ x\end{array}\right) \frac{q_{0}^{k-x}\left(1-q_{0}\right)^{x}}{2^{x}}$ and $\beta\left(q_{0}, k\right)=\sum_{x=1}^{k}\left(\begin{array}{l}k \\ x\end{array}\right) \frac{q_{0}^{k-x}\left(1-q_{0}\right)^{x}}{2^{x-1}}$; the expected utility a consumer gets from the two distinct search alternatives is:

$$
\begin{aligned}
E u\left(q_{1}=1\right)= & \tilde{p}-\alpha\left(q_{0}, k\right) E(p)-\left(1-\alpha\left(q_{0}, k\right)\right) E_{\min }(p)-c \\
E u\left(q_{0}=1\right)= & \tilde{p}\left(1-q_{0}^{k}\right)-\beta\left(q_{0}, k\right) E(p)- \\
& -\left(1-q_{0}^{k}-\beta\left(q_{0}, k\right)\right) E_{\min }(p)
\end{aligned}
$$

The interpretation of expression (10) is the following. Since a consumer searches once on its own he always buys: he buys at the expected price whenever his neighbors provide redundant or no information; otherwise he buys at the expected minimum price. Differently, a consumer who does not search, expression (11), buys only when at least one of his social contact searches, $\left(1-q_{0}^{k}\right)$.

In equilibrium every consumer must be indifferent between searching once and not searching at all, i.e $E u\left(q_{1}=1\right)=E u\left(q_{0}=1\right)$. This condition is satisfied if and only if:

$$
\frac{\left(1+q_{0}\right)^{k}-2^{k+1} q_{0}^{k}}{2^{k}}\left[E(p)-E_{\min }(p)\right]+q_{0}^{k}\left(\tilde{p}-E_{\min }(p)\right)=c
$$

The interpretation of (12) is similar to the interpretation of (6). The next result shows that for moderate value of search costs there exists at least a stable low search intensity equilibrium.

Theorem 5.1. For any $k>0$ there exists a $\tilde{c}$ such that for any $c \in(\bar{c}(k), \tilde{c}) a$ stable low search intensity equilibrium exists where firms behave according to Proposition 5.1 and $q_{0}^{*}$ is the smallest solution of (12).

Theorem 5.1 tells us that for moderate search costs there exists at least a stable solution of the equilibrium condition (12). The proof in the appendix also shows that there always exists at least another solution of the equilibrium condition (12), which however is not stable. Further, numerical simulations reveal that these are the only 
two possible solutions. In what follows we focus on the stable equilibrium. We start with a discussion of the existence of the low search intensity equilibrium. In Figure 5 below we plot the LHS of the equilibrium condition (12) with respect to $q_{0}$ for different levels of $k$.

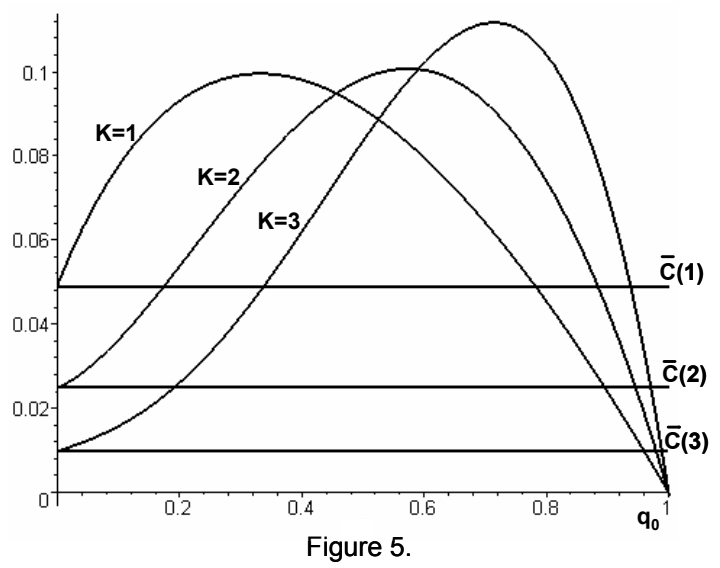

We note that for any positive $k$ the stable low search intensity equilibrium exists for search costs which are higher than $\bar{c}(k)$. Moreover, when the search cost is exactly equal to $\bar{c}(k)$ in equilibrium consumers search once with probability one and the low and high search intensity equilibrium coincide. ${ }^{15}$

We now turn to examine the local comparative statics with respect to $k$. The intractability of the equilibrium condition (12), leads us to rely on numerical simulations. The findings are summarized in the following remark. ${ }^{16}$

Remark 5.1. Suppose we move from $k$ to $k+1$ and assume that $c \in(c(k), \tilde{c})$. Then: (a) consumers search less frequently, i.e. $q_{0}$ increases, $(b)$ expected price decreases, (c) social welfare decreases and (d) consumer surplus increases.

The numerical simulations confirm that consumers free-ride more on each other in denser networks. However, in sharp contrast with the high search intensity equilibrium, the effect on market competitiveness is reverse: the higher the density of the network, the lower the expected price. The reason behind this difference is that in the low search intensity equilibrium if a consumer free rides on others (does not search) he may not be able to buy at all. This risk disincentives consumers from free-riding. Thus, when the degree of the network increases the expected number of

\footnotetext{
${ }^{15} \mathrm{It}$ is readily seen that the price distributions in Proposition 4.1 and 5.1 and the equilibrium conditions (6) and (12) coincide when $q_{1}=1$ (i.e. $q_{0}=1$ ).

${ }^{16}$ We have run simulations for $k=1, \ldots, m-1$, for different value of $m$. For any $(k, m)$ we first determine the range of the search costs for which the stable equilibrium exists (the smaller solution of (12)), say $\left[c_{1}(k), c_{2}(k)\right]$. Next, for each $c \in\left[c_{1}(k), c_{2}(k)\right]$, we derive the stable solution of equation $(12), q_{0}(k, c)$. Finally, using this value we compute the expected price, social welfare and consumer surplus.
} 
fully informed consumers in the economy increases. As firms compete more often for consumers, they charge on average lower prices. Figure 6a below shows the expected equilibrium price for different network degrees. Figure $6 \mathrm{~b}$ illustrates the equilibrium probability of not searching for different network degrees.
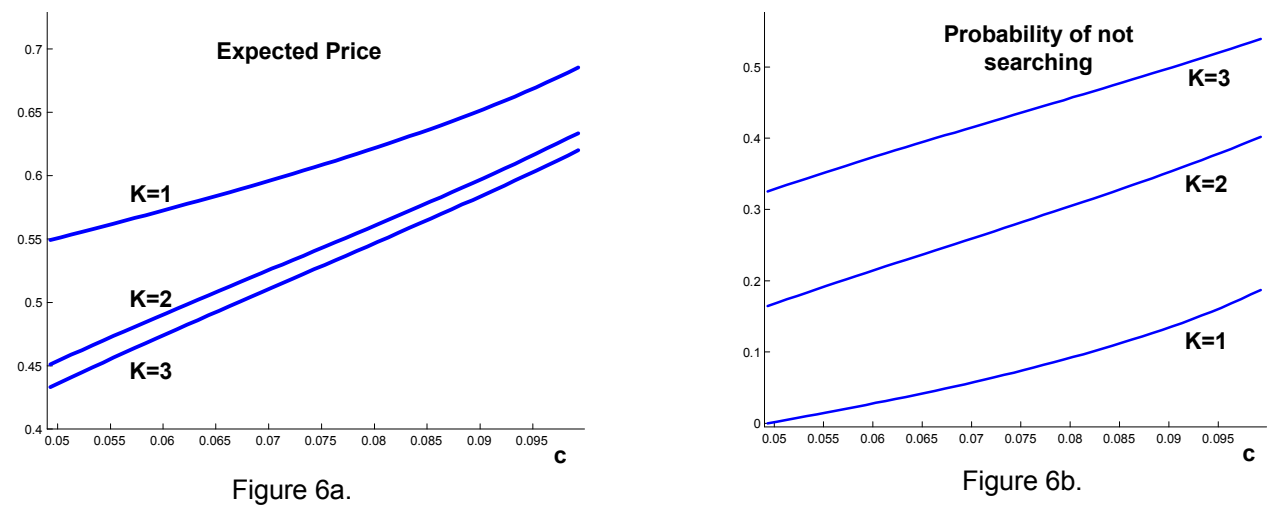

Next, we note that total social welfare is decreasing in the density of the network. Figure $6 \mathrm{c}$ plot the social welfare for different degrees of the network. Again, the reason is that a consumer who completely relies on his connections takes the risk to be ex-post completely ignorant about prices. In such a case a transaction does not take place and this generates substantial welfare losses from the society standpoint. When the degree of the network increases this negative effect dominates the realized savings in search cost. Interestingly, even if social welfare decreases, consumers surplus increases in the density of the network. Figure $6 \mathrm{~d}$ depicts the consumer surplus for different degrees of the network. Two are the driving forces for this result. The expected price and expected minimum price decrease in the density of the network. Further, the overall increase of information shared in the network leads consumers to be more likely to compare prices.

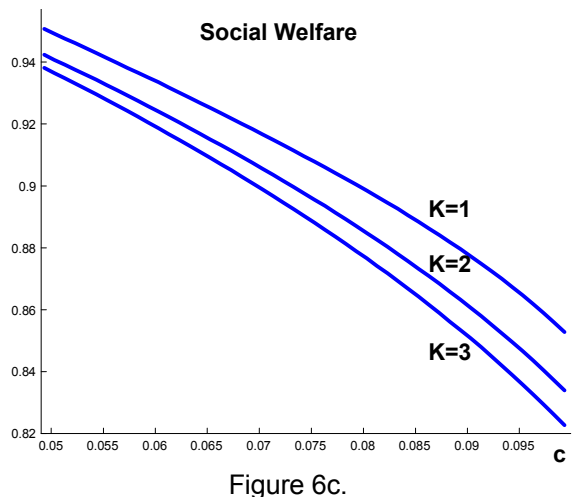

Figure 6c.

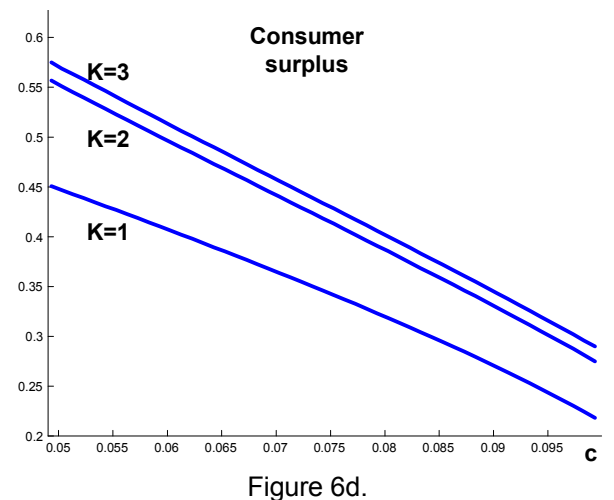

Figure 6d. 


\section{Discussion: asymmetric strategies}

So far we have focused on symmetric strategy profiles. It is worth noting that, under such restriction, the equilibrium characterization is insensitive to the (symmetric) allocation of links; that is the characterization of symmetric equilibria is equivalent for every regular network of degree $k$. Exploiting this property, we can study, by means of comparative static, how local information sharing affects market functioning. ${ }^{17}$ Can we say something about asymmetric equilibria? In what follows we provide an example which illustrates the nature of equilibria where consumers employ asymmetric pure strategies. We shall note that when considering asymmetric strategies, even in symmetric graphs, the way that links are allocated across consumers matters for equilibrium.

Consider a population composed of 8 consumers. Figure 7 depicts two symmetric networks with equal degree 4 . The network on the LHS represents a social structure with overlapping neighborhoods, while the graph on the RHS represents a social structure where each consumer has links with their immediate neighborhood as well as more distant links (short-cuts). A black node indicates a consumer who searches once, while a white node an inactive consumer.

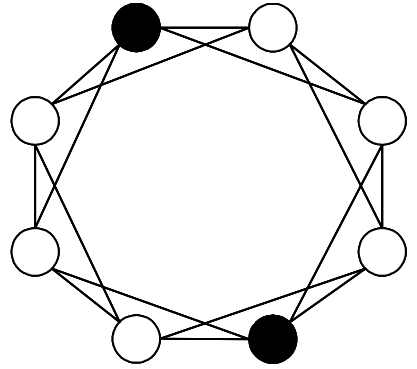

Overlapping Neighbourhoods

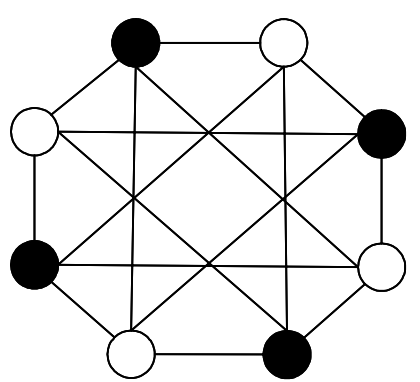

Short-cuts

Figure 7.

It is possible to show that the depicted pattern of consumers' search in each of the network is the only possible pattern for an asymmetric equilibrium to exist. It is also easy to show that an equilibrium exists where firms price randomly in both situations. There are three remarks worth doing. The first is that in both networks only specialized equilibria exist: some consumers search once (expert consumers), while others do not search at all (free-rider consumers). This contrasts with the findings

\footnotetext{
${ }^{17}$ We would like to emphasize that the model can be re-interpreted in the following way. Consider the game introduced in Section 2, but, instead of assuming that consumers are embedded in a network, let us assume that each consumer, before choosing if and where to buy, receives price information from $k$ randomly sampled consumers. It is easy to see that the results provided so far apply to this new setting and that they provide a complete equilibrium characterization of the game.
} 
of Bramoulle and Kranton (2004), who show that also distributed equilibria arise. ${ }^{18}$ The reason for these differences is that in the current paper the benefits of searching depend on firms pricing behavior, while in their paper the benefits are exogenously given. This reduces dramatically the multiplicity of equilibria Bramoulle and Kranton (2004) obtain. Second, when the network has overlapping neighborhoods a fewer number of experts arise in the economy as compared to the case where consumers have also short-cuts. This is a consequence of the following equilibrium property: experts can only be linked with free-riders. ${ }^{19}$ This suggests that the maximum number of experts which can be sustained in equilibrium is somewhat negatively related to the clustering (the number of trials) of a network. Third, in both networks we have price dispersed equilibria, which again arise because consumers are ex-post asymmetrically informed.

In this specific example, we can then ask how the different allocation of links across consumers affect strategic pricing, consumers' welfare and social welfare. It is easy to show that the equilibrium price distribution for the short-cuts network first order stochastic dominate the one associated with the overlapping neighbors network. ${ }^{20}$ Therefore expected prices are lower in the former case as compared to the latter. Note that the presence of short-cuts allow for the emergence of more experts in the economy which in turn increases firms' competition. It is also possible to show that aggregate consumers welfare is higher in the presence of short-cuts as compared to overlapping neighborhoods. ${ }^{21}$ This is because the increase on firms' competition due to the higher number of experts dominates the associated increasing in the total search cost. Finally, it is readily seen that social welfare is higher in the network with overlapping neighborhoods because the total search cost is minimized and yet each transaction takes place.

\section{Conclusion}

We have developed a simple search model which studies the effects between networks and markets in mediating externalities among economic agents. Even if quite stylized, the model provides new and interesting insights. It shows that an increase in information sharing generates two important effects. The first is that, if consumers' search effort remains the same, firms will price more aggressively as more consumers

\footnotetext{
${ }^{18}$ Roughly speaking a distributed configuration in this model is one where there are consumers who search surely but with different search intensities.

${ }^{19}$ Formally, the set of experts in equilibrium must form a maximally independent set. Given a graph $g$ an independent set is a set of nodes which are not directly connected. A maximally independent set is an independent set which is not a proper subset of any other independent set.

${ }^{20}$ Formally, the equilibrium price distribution in case of the overlapping neighborhoods network is $F^{O}(p)=1-(9 / 2)(v-p) / p, \forall p \in[(9 / 11) v, v]$. In the case of the short-cuts network $F^{S}(p)=$ $1-(17 / 14)(v-p) / p, \forall p \in[(17 / 31) v, v]$.

${ }^{21}$ To see this note that the aggregate consumers surplus in the case of overlapping neighbors is $c s^{O}=9 \ln \frac{11}{9}-1-2 c$, which in the case of short-cuts is $c s^{S}=-\frac{1}{2}+\frac{34}{7} \ln \frac{31}{17}-4 c$.
} 
are fully informed. The second effect is that consumers free ride on others, thereby decreasing firms' competition. The magnitude of these two opposite effects determines market competitiveness. We find a systematic relation between the level of search costs and the effect of information sharing, which crucially relies on the risk consumers face when they free-ride. Specifically, when search costs are sufficiently low, in equilibrium consumers always search, which implies that free-riding is relatively inexpensive. This creates high incentives to free-ride and therefore an increasing information sharing is detrimental for consumers. As soon as search costs become high enough, for an equilibrium consumers will not search with positive probability. In turn, this disincentives consumers to free-ride on each other.

There are many extensions which may be of interest for further research. The first is to examine sequential search: consumers search and observe a price quotation and then they decide whether to search more (Stahl 1989). While when the network is empty there exists a unique equilibrium where consumers surely search for one price quotation, it is easy to show that as soon as consumers can exchange some information a low search intensity equilibrium arises for sufficiently high search costs. The study of how market competition varies with network degree is an open question. A second extension would be to endogenize the quality of information sharing. It is natural to think that the quality of each link and therefore how information flow from one consumer to the other depends on the time the two parties are willing to invest on. In this new settings one could investigate the strategic nature between network investment and private search investment and the implications on market functioning. Third, it is interesting to generalize the model to an oligopoly. Clearly, the magnitude of the two effects we have mentioned above will depend on the number of firms present in the market. While in the current paper the focus is on the effect of an increase in network connectivity on market competitiveness, a natural question would be to ask what happens when the market becomes less concentrated. Finally, one could investigate the role consumers networks play in shaping the incentive of firms to generate information, for example advertising. When firms must decide their advertising strategy they face the following trade-off. On the one hand advertising increases the demand of a firm, on the other hand it increases firms' competition and therefore it reduces prices. These two effects will likely depend on the architectural properties of consumers networks.

\section{References}

[1] Anderson S. P. and R. Renault (2000), Consumer Information and Firm Pricing: Negative Externalities From Improved Information, International Economic Review, 41, 3, 721-742. 
[2] Bala V. and S. Goyal (1998), Learning from Neighbours, Review of Economic Studies, 65, 595-621.

[3] Ballester C., A. Calvo and Y. Zenou (2004), Who's whom in crime networks? mimeo, University Autonoma of Barcelona.

[4] H. Bester (1994), Price Commitment in Search Markets, Journal of Economic Behavior and Organization, 25, 109-120.

[5] Y. Bramoulle and R. Kranton (2004), A Network Model of Public Goods: Experimentation and Social Learning, mimeo.

[6] A. Braverman (1980), Consumer Search and Alternative Market Equilibria, The Review of Economic Studies, 47, 487-502.

[7] K. Burdett and M. G. Coles (1997), Steady State Price Distribution in a Noisy Search Equilibrium, Journal of Economic Theory, 72, 1-32.

[8] K. Burdett and K.L. Judd (1983), Equilibrium Price Dispersion, Econometrica, 51-4, 955-69.

[9] Calvo-Armengol T. and M. Jackson (2004a), The Effects of Social Networks on Employment and Inequality, The American Economic Review, forthcoming.

[10] J. Coleman (1966), Medical Innovation: A diffusion study. Bobbs-Merrill, New York.

[11] L. F. Feick and L.L. Price (1986), The Market Maven: A Best Prospect for Targeting Marketing Communications, Managing, 10-14.

[12] L. F. Feick and L.L. Price (1987), The Market Maven: A Diffuser of Marketplace Information, Journal of Marketing, 51-1, 83-97.

[13] C. Fershtman and A. Fishman (1992), Price Cycles and Booms: Dynamic Search Equilibrium, The American Economic Review, 82-5, 1221-1233.

[14] S. Goyal and S. Joshi (2003), Networks of Collaboration in Oligopoly, Games and Economic Behavior, 43, 57-85.

[15] S. Goyal and J.L. Moraga-Gonzalez (2001), R\&D Networks, Rand Journal of Economics, 32-4, 686-707.

[16] M. Granovetter (1974), Getting a job: A study of contacts and careers. University of Chicago Press, Chicago.

[17] M. Jackson and A. Wolinsky (1996), A Strategic Model of Social and Economic Networks, Journal of Economic Theory, 71, 44-74. 
[18] M. Janssen and J.L. Moraga-Gonzalez (2003), Strategic Pricing, Consumer Search and the Number of Firms, Forthcoming The Review of Economic Studies.

[19] Kranton, R., and D. F. Minehart (2001), A Theory of Buyer-Seller Networks, The American Economic Review, 91, 485-508.

[20] Morgan and Manning (1985), Optimal Search, Econometrica, 53-4, 923-944.

[21] D. O. Stahl II (1989), Oligopolistic Pricing with Sequential Consumer Search, The American Economic Review, 79-4, 700-12.

[22] D. O. Stahl II (1996), Oligopolistic Pricing with Heterogeneous Consumer Search, International Journal of Industrial Organization, 14, 243-268.

[23] Topa, G. (2001), Social Interactions, Local Spillovers and Unemployment, Review of Economic Studies, 68, 2, 261-295.

\section{Appendix}

\section{Proof of Proposition 3.1.}

First, it is easy to verify that the strategy profile $\left\{p, q_{0}=1\right\}$, where $p \in[\tilde{p}-c, \tilde{p}]$ is a Nash equilibrium. I now prove that these are the only (generic) equilibria in which consumers employ pure strategies. There are two possibilities, which I analyze in turn. First, suppose $q_{1}=1$; if $k=0$, then each consumer will observe only one price and as a consequence firms will charge $p=\tilde{p}$. However, as far as $c>0$, a consumer strictly gains by not searching at all. Consider then that $k>0$; I claim that if this were an equilibrium then firms would price according to an atomless price distribution $F(p)$ defined on a convex support $\sigma$. The reason is that since $k>0$ and $q_{1}=1$ there is a fraction of consumers which will observe both firms' prices with a strictly positive probability. Therefore, if firms charge a price $p$ with a mass point, they will tight at that price with strictly positive probability, but then an individual firm has a strict incentive to undercut the atom. I now show that, given $k>0$, an equilibrium where consumers search once with probability one, i.e. $q_{1}=1$, exists for a unique value of the search cost, i.e. it is not generic. The utility to a consumer is $E u\left(q_{1}=1\right)=\tilde{p}-\frac{1}{2^{k}} E(p)-\left(1-\frac{1}{2^{k}}\right) E_{\min }(p)-c$. In equilibrium it must be the case that $E u\left(q_{1}=1\right) \geq E u^{d}\left(q_{x}=1\right), x=0,2$, where $E u^{d}\left(q_{0}=1\right)=\tilde{p}-\frac{1}{2^{k-1}} E(p)-\left(1-\frac{1}{2^{k-1}}\right) E_{\min }$ and $E u^{d}\left(q_{2}=1\right)=\tilde{p}-E_{\min }(p)-2 c$. Solving the two inequalities I obtain that:

$$
c=\frac{1}{2^{k}}\left(E(p)-E_{\min }\right)
$$

Second, suppose $q_{2}=1$ and $k \geq 0$. It is easy to see that each consumer will observe always two prices. If this were an equilibrium firms would charge the competitive 
price, $p=0$. However, a consumer is strictly better-off by searching only once. This completes the proof of the Proposition.

\section{Proof Proposition 3.2.}

I first show that firms price according to an atomless price distribution $F(p)$. If $k=0$ the model degenerates to the duopoly version of Burdett and Judd (1983) and the claim follows. Next, assume $k>0$ and suppose there exists some price $p^{*}$ with a mass point. Since consumers search at least once with some positive probability and $k>0$, it follows that a fraction of consumers observe two prices with strictly positive probability. Therefore, firms would tie at the price $p^{*}$ with strictly positive probability; in such a case a firm gains by undercutting $p^{*}$. This is a contradiction. I finally show that for any $k \geq 0$ the support $\sigma$ must be convex. Suppose not, i.e. $\exists \tilde{\sigma} \varsubsetneqq \sigma: F(p)=\eta \forall p \in \tilde{\sigma}, \eta \in[0, \tilde{p}]$. Let $p^{*}=\inf \tilde{\sigma}$, then a firm charging $p^{*}$ gains by increasing such price. This completes the proof of the first part of the Lemma.

I now show that if $k>0$ in any equilibrium either $q_{1}+q_{2}=1, q_{1}, q_{2} \in(0,1)$ or $q_{0}+q_{1}=1, q_{0}, q_{1} \in(0,1)$. I start by claiming that $q_{0}+q_{2}=1$ cannot be part of an equilibrium. Suppose it is, then firms would set the competitive price with probability one. The reason is that the expected demand of a firm derives from two sources: consumers who search on their own and consumers who do not search but obtain information from their social contacts. The former would always observe two prices, while the latter either do not observe any price or they also observe two prices. Using a standard undercutting argument it follows that firms must charge the competitive price. Since firms charge the competitive price with probability one a consumer strictly benefits by searching only once.

Next I show that $q_{0}+q_{1}+q_{2}=1$ cannot be part of an equilibrium. Suppose it is an equilibrium; the same argument above implies that $F(p)$ is atomless and it is defined on a convex support $\sigma$. In equilibrium it must be the case that $E u\left(q_{x}=1\right)=$ $E u\left(q_{y}=1\right), x, y=0,1,2$. Let $\alpha(k)=\sum_{x=1}^{k}\left(\begin{array}{l}k \\ x\end{array}\right) \frac{q_{0}^{k-x} q_{1}^{x}}{2^{x}}$, then I obtain that:

$$
\begin{aligned}
& E u\left(q_{0}=1\right)=\tilde{p}\left(1-q_{0}^{k}\right)-\alpha(k) E(p)-\left(1-q_{0}^{k}-\alpha(k)\right) E_{\min }(p) \\
& E u\left(q_{1}=1\right)=\tilde{p}-\left(q_{0}^{k}+\frac{\alpha(k)}{2}\right) E(p)-\left(1-q_{0}^{k}-\frac{\alpha(k)}{2}\right) E_{\min }(p)-c \\
& E u\left(q_{2}=1\right)=\tilde{p}-E_{\min }(p)-2 c
\end{aligned}
$$

Solving for the equilibrium conditions it follows that:

$$
q_{0}^{k}[\tilde{p}-E(p)]=q_{0}^{k}\left[E(p)-E_{\min }(p)\right]
$$

Given that $q_{0}>0$ this condition is satisfied if and only if $\tilde{p}-E(p)=E(p)-E_{\min }(p)$. I now show that this is impossible. To see this I note that

$$
E_{\min }(p)=2 E(p)-\int_{\underline{p}}^{\tilde{p}} 2 p f(p) F(p) d p
$$


Therefore:

$$
E(p)-E_{\min }(p)=\int_{\underline{p}}^{\tilde{p}} 2 p f(p) F(p) d p-E(p)=
$$

Integrating by parts I can show that:

$$
\int_{\underline{p}}^{\tilde{p}} 2 p f(p) F(p) d p=\tilde{p}-\int_{\underline{p}}^{\tilde{p}}[F(p)]^{2} d p
$$

which implies that:

$$
E(p)-E_{\min }(p)=[\tilde{p}-E(p)]-\int_{\underline{p}}^{\tilde{p}}[F(p)]^{2} d p<[\tilde{p}-E(p)]
$$

This is a contradiction and therefore the claim follows. Hence, the proof for the case $k \geq 1$ is complete.

I finally consider the case where $k=0$. The same argument used for $k \geq 1$, shows that $q_{0}+q_{2}=1$ and $q_{0}+q_{1}+q_{2}=1$ cannot be part of an equilibrium. Therefore, the only possibility left is $q_{0}+q_{1}=1$. If this were an equilibrium firms would charge the monopolist price. However, in such a case consumers cannot be indifferent between not searching and searching once, i.e. $E u\left(q_{0}=1\right)=0>-c=E u\left(q_{1}=1\right)$. This completes the proof of the Proposition.

\section{High Search Intensity Equilibrium}

\section{Proof of Proposition 4.1.}

I first note that the upper bound of the price distribution must be the reservation price, $\tilde{p}$; for otherwise a firm charging $\bar{p}<\tilde{p}$ strictly gains by increasing it. This implies that the expected equilibrium profit is: $E \pi_{i}^{*}\left(\tilde{p}, p_{j} ; k, q_{1}\right)=\frac{m q_{1}^{k+1}}{2^{k+1}} \tilde{p}$. In equilibrium a firm $i$ must be indifferent between charging any price in the support $\sigma$, i.e. $E \pi_{i}\left(p_{i}, p_{j} ; k, q_{1}\right)=E \pi_{i}^{*}\left(\tilde{p}, p_{j} ; k, q_{1}\right), \forall p \in \sigma$. Solving this condition I obtain the expression of $F\left(p ; k, q_{1}\right)$ and the expression of the lowerbound of the support is obtained by solving for $E \pi_{i}\left(\underline{p}_{i}, p_{j} ; k, q_{1}\right)=E \pi_{i}^{*}\left(\tilde{p}, p_{j} ; k, q_{1}\right)$. Finally, let $\psi=\frac{q_{1}^{k+1}}{2\left(2^{k}-q_{1}^{k+1}\right)}$, then it is easy to see that $\frac{\partial F\left(p ; k, q_{1}\right)}{\partial k}>0$ if and only if $\frac{\partial \psi}{\partial k}=\frac{q_{1}^{k+1} 2^{k-1}}{\left(2^{k}-q_{1}^{k+1}\right)^{2}} \ln \frac{q_{1}}{2}<0$. This completes the proof.

\section{Proof Theorem 4.1.}

The proof of the case $k=0$ is the same as Burdett and Judd(1983) and therefore it is omitted. I focus instead in the case $k>0$.

Let us define the RHS of expression (6) as $\phi\left(p ; k, q_{1}\right)=\frac{q_{1}^{k}}{2^{k}}\left[E(p)-E_{\min }(p)\right]$. I start by showing that $\frac{\partial \phi\left(p ; k, q_{1}\right)}{\partial q_{1}}>0$. Suppose, without loss of generality that $\tilde{p}=1$. Using the expression of the price distribution $F\left(p ; k, q_{1}\right)$ defined in proposition 5.3. I can 
invert it to obtain:

$$
p(z ; k, q)=\frac{1}{g\left(z ; k, q_{1}\right)}
$$

where

$$
g\left(z ; k, q_{1}\right)=1+\frac{2\left(2^{k}-q^{k+1}\right)}{q^{k+1}}(1-z)
$$

I now note that:

$$
\frac{2^{k}}{q_{1}^{k}} \phi\left(p ; k, q_{1}\right)=2 \int_{\underline{p}\left(k, q_{1}\right)}^{1} p f\left(p ; k, q_{1}\right)\left(1-F\left(p ; k, q_{1}\right)\right) d p-\int_{\underline{p}\left(k, q_{1}\right)}^{1} p f\left(p ; k, q_{1}\right) d p
$$

Integrating by parts yields,

$$
\frac{2^{k}}{q_{1}^{k}} \phi\left(p ; k, q_{1}\right)=\int_{\underline{p}\left(k, q_{1}\right)}^{1}\left[F\left(p ; k, q_{1}\right)\left(1-F\left(p ; k, q_{1}\right)\right)\right] d p
$$

Using the inverse function $p\left(z ; k, q_{1}\right)$, I can write this expression as:

$$
\frac{2^{k}}{q_{1}^{k}} \phi\left(z ; k, q_{1}\right)=\int_{0}^{1}\left[p\left(\sqrt{z} ; k, q_{1}\right)-p\left(z ; k, q_{1}\right)\right] d z
$$

Or,

$$
\frac{2^{k}}{q_{1}^{k}} \phi\left(z ; k, q_{1}\right)=\int_{0}^{1} p\left(z ; k, q_{1}\right)(2 z-1) d z
$$

Let $a=q^{k+1}, b=2\left(2^{k}-q^{k+1}\right)$ and $c=2^{k+1}(2 k+1)$, then,

$$
\begin{aligned}
\frac{2^{k}}{q_{1}^{2 k}} \frac{\partial \phi\left(z ; k, q_{1}\right)}{\partial q_{1}}= & \int_{0}^{1} \frac{[k a(2 z-1)+c(1-z)](2 z-1)}{[a+b(1-z)]^{2}} d z \\
= & -\int_{0}^{1 \backslash 2} \frac{[k a(2 z-1)+c(1-z)](1-2 z)}{[a+b(1-z)]^{2}} d z+ \\
& +\int_{1 \backslash 2}^{1} \frac{[k a(2 z-1)+c(1-z)](2 z-1)}{[a+b(1-z)]^{2}} d z
\end{aligned}
$$

I note that $\frac{[k a(2 z-1)+c(1-z)]}{[a+b(1-z)]^{2}}$ is positive and increasing in $z$ for any $z \in(0,1 / 2)$ and that $[a+b(1-z)]^{2}$ is decreasing in $z$. Therefore:

$$
\frac{2^{k}}{q_{1}^{2 k}} \frac{\partial \phi\left(z ; k, q_{1}\right)}{\partial q_{1}}>-\int_{0}^{1 \backslash 2} \frac{2^{k}(2 k+1)(1-2 z)}{2^{2 k}} d z+\int_{1 \backslash 2}^{1} \frac{[k a(2 z-1)+c(1-z)](2 z-1)}{2^{2 k}} d z
$$


I now note that $[k a(2 z-1)+c(1-z)]$ is positive and it is decreasing in $z$, which implies that:

$$
\begin{aligned}
\frac{2^{k}}{q_{1}^{2 k}} \frac{\partial \phi\left(z ; k, q_{1}\right)}{\partial q_{1}} & >-\int_{0}^{1 \backslash 2} \frac{2^{k}(2 k+1)(1-2 z)}{2^{2 k}} d z+\int_{1 \backslash 2}^{1} \frac{q_{1}^{k+1} k(2 z-1)}{2^{2 k}} d z \\
& >\left(\frac{2^{k}(2 k+1)+q_{1}^{k+1} k}{2^{2 k}}\right) \int_{0}^{1}(2 z-1) d z \\
& >\left(\frac{2^{k}(2 k+1)+q_{1}^{k+1} k}{2^{2 k}}\right)\left(\frac{(2 z-1)^{2}}{4}\right)_{0}^{1}=0
\end{aligned}
$$

Next, I note that $\lim _{q \rightarrow 0} \phi\left(p ; k, q_{1}\right)=0$ and that $\lim _{q \rightarrow 1} \phi\left(p ; k, q_{1}\right)=\bar{c}(k)$. The facts that $\frac{\partial \phi\left(z ; k, q_{1}\right)}{\partial q_{1}}>0, \lim _{q \rightarrow 0} \phi\left(p ; k, q_{1}\right)=0$ and $\lim _{q \rightarrow 1} \phi\left(p ; k, q_{1}\right)=\bar{c}(k)$ imply that for any $c \in(0, \bar{c}(k))$ there exists a unique solution, say $q_{1}^{*} \in(0,1)$, of the equilibrium condition $(6)$, i.e. $\phi\left(p ; k, q_{1}^{*}\right)=c$.

I finally show that consumers do not want to deviate. Given that all consumers randomize between searching once and twice, the expected utility to a consumer who deviates by not searching at all is:

$$
E u^{d}\left(q_{0}=1\right)=\tilde{p}-\frac{q_{1}^{k}}{2^{k-1}} E(p)-\left(1-\frac{q_{1}^{k}}{2^{k-1}}\right) E_{\min }(p)
$$

For an equilibrium it must be the case that $E u^{d}\left(q_{0}=1\right) \leq E u\left(q_{1}=1\right)$. Using the expression (4) it follows that this deviation is not profitable if and only if:

$$
c \leq \frac{q_{1}^{k}}{2^{k}}\left[E(p)-E_{\min }(p)\right]
$$

This condition is always satisfied because in equilibrium $c=\frac{q_{1}^{k}}{2^{k}}\left[E(p)-E_{\min }(p)\right]$. This completes the proof of the Theorem.

\section{Proof Proposition 4.2.}

I recall that the RHS of the equilibrium condition (6) may be written as:

$$
\phi\left(z ; k, q_{1}\right)=\int_{0}^{1} \frac{q_{1}^{k}}{2^{k}} p\left(z ; k, q_{1}\right)(2 z-1) d z
$$

First, I show that $\frac{\partial \phi\left(z ; k, q_{1}\right)}{\partial k}<0$. The derivative of $\phi\left(z ; k, q_{1}\right)$ with respect to $k$ is:

$$
\begin{aligned}
\frac{\partial \phi\left(z ; k, q_{1}\right)}{\partial k}= & -\frac{q_{1}^{2 k+1}}{2^{k}} \ln \frac{2}{q_{1}} \int_{0}^{1}\left(\frac{q_{1}^{k+1}+2\left(2^{k+1}-q_{1}^{k+1}\right)(1-z)}{\left[q_{1}^{k+1}+2\left(2^{k}-q_{1}^{k+1}\right)(1-z)\right]^{2}}\right)(2 z-1) d z+ \\
& +\frac{q_{1}^{2 k+1}}{2^{k}} \ln q_{1} \int_{0}^{1} \frac{q_{1}^{k+1}(2 z-1)^{2}}{\left[q_{1}^{k+1}+2\left(2^{k}-q_{1}^{k+1}\right)(1-z)\right]^{2}} d z
\end{aligned}
$$


I note that the second term of this expression is weakly negative and that $-\frac{q_{1}^{2 k+1}}{2^{k}} \ln \frac{2}{q_{1}}$ is also weakly negative. Therefore it is sufficient to show that:

$$
\xi=\int_{0}^{1}\left(\frac{q_{1}^{k+1}+2\left(2^{k+1}-q_{1}^{k+1}\right)(1-z)}{\left[q_{1}^{k+1}+2\left(2^{k}-q_{1}^{k+1}\right)(1-z)\right]^{2}}\right)(2 z-1) d z>0
$$

To see this note that:

$$
\begin{aligned}
\xi= & -\int_{0}^{1 / 2}\left(\frac{q_{1}^{k+1}+2\left(2^{k+1}-q_{1}^{k+1}\right)(1-z)}{\left[q_{1}^{k+1}+2\left(2^{k}-q_{1}^{k+1}\right)(1-z)\right]^{2}}\right)(1-2 z)+ \\
& +\int_{1 / 2}^{1}\left(\frac{q_{1}^{k+1}+2\left(2^{k+1}-q_{1}^{k+1}\right)(1-z)}{\left[q_{1}^{k+1}+2\left(2^{k}-q_{1}^{k+1}\right)(1-z)\right]^{2}}\right)(1-2 z)
\end{aligned}
$$

Since $\left(\frac{q_{1}^{k+1}+2\left(2^{k+1}-q_{1}^{k+1}\right)(1-z)}{\left[q_{1}^{k+1}+2\left(2^{k}-q_{1}^{k+1}\right)(1-z)\right]^{2}}\right)$ is increasing in $z$ for $z \in(0,1 / 2)$ and $\left[q_{1}^{k+1}+2\left(2^{k}-q_{1}^{k+1}\right)(1-z)\right]$ is decreasing in $z$, then:

$$
\xi>-\int_{0}^{1 / 2}\left(\frac{2^{k+1}}{2^{2 k}}\right)(1-2 z)+\int_{1 / 2}^{1}\left(\frac{q_{1}^{k+1}+2\left(2^{k+1}-q_{1}^{k+1}\right)(1-z)}{2^{2 k}}\right)(1-2 z)
$$

Furthermore, $q_{1}^{k+1}+2\left(2^{k+1}-q_{1}^{k+1}\right)(1-z)$ is also decreasing in $z$, which implies that

$$
\begin{aligned}
\xi & >-\int_{0}^{1 / 2} \frac{2^{k+1}}{2^{2 k}}(1-2 z)+\int_{1 / 2}^{1} \frac{q_{1}^{k+1}}{2^{2 k}}(1-2 z)= \\
& =\frac{2^{k+1}+q_{1}^{k+1}}{2^{2 k}} \int_{0}^{1}(2 z-1) d z \\
& =\frac{2^{k+1}+q_{1}^{k+1}}{2^{2 k}}\left(\frac{(2 z-1)^{2}}{4}\right)_{0}^{1}=0
\end{aligned}
$$

The fact that $\frac{\partial \phi\left(z ; k, q_{1}\right)}{\partial k}<0$ and that $\frac{\partial \phi\left(z ; k, q_{1}\right)}{\partial q_{1}}>0$ implies that if $k$ increases then $q_{1}$ must also increase.

Second, I show that if $k$ increases, then expected prices increase as well. Let $\psi\left(k, q_{1}\right)=$ $\frac{q_{1}^{k+1}}{2\left(2^{k}-q_{1}^{k+1}\right)}$, then the expression of the price distribution defined in Proposition 4.1 can be rewritten as:

$$
F(p)=1-\psi \frac{\tilde{p}-p}{p}
$$

To prove the claim it is enough to show that:

$$
\frac{d \psi}{d k}=\frac{\partial \psi}{\partial k}+\psi \frac{\partial q_{1}}{\partial k}>0
$$


I denote $\phi_{k}\left(k, q_{1}\right)=\partial \phi\left(k, q_{1}\right) / \partial k$ and $\phi_{q_{1}}\left(k, q_{1}\right)=\partial \phi\left(k, q_{1}\right) / \partial q_{1}$. Using the equilibrium condition $\phi\left(k, q_{1}\right)-c=0$ and applying the implicit function theorem I can derive

$$
\frac{\partial q}{\partial k}=-\frac{\phi_{k}(\cdot)}{\phi_{q_{1}}(\cdot)}
$$

where

$$
\begin{aligned}
\phi_{k}\left(k, q_{1}\right) & =-\frac{q_{1}^{k}}{2^{k}} \ln \frac{2}{q_{1}} \psi\left[(1+2 \psi) \ln \frac{1+\psi}{\psi}-2\right]+\frac{q_{1}^{k}}{2^{k}} \psi_{k}\left[(1+4 \psi) \ln \frac{1+\psi}{\psi}-\frac{3+4 \psi}{1+\psi}\right] \\
\phi_{q_{1}}\left(q_{1}, k\right) & =\frac{k q_{1}^{k-1}}{2^{k}} \psi\left[(1+2 \psi) \ln \frac{1+\psi}{\psi}-2\right]+\frac{q_{1}^{k}}{2^{k}} \psi_{q_{1}}\left[(1+4 \psi) \ln \frac{1+\psi}{\psi}-\frac{3+4 \psi}{1+\psi}\right]
\end{aligned}
$$

Plugging the expressions $\frac{\partial q_{1}}{\partial k}$ in $\frac{d \psi}{d k}$, I obtain that

$$
\frac{d \psi}{d k}=\frac{\psi}{\phi_{q_{1}}}\left(\left((1+2 \psi) \ln \frac{1+\psi}{\psi}-2\right)\left(\psi_{k} \frac{k q^{k-1}}{2^{k}}+\psi_{q_{1}} \frac{q_{1}^{k}}{2^{k}} \ln \frac{2}{q_{1}}\right)\right)
$$

Since $\phi_{q_{1}}$ and $\psi\left(q_{1}, k\right)$ are strictly positive it follows that $\frac{d \psi}{d k}>0$ if and only if

$$
\left((1+2 \psi) \ln \frac{1+\psi}{\psi}-2\right)\left(\psi_{k} \frac{k q_{1}^{k-1}}{2^{k}}+\psi_{q_{1}} \frac{q_{1}^{k}}{2^{k}} \ln \frac{2}{q_{1}}\right)>0
$$

Computing the derivatives $\psi_{k}=-\frac{q_{1}^{k+1} 2^{k}}{2\left(2^{k}-q_{1}^{k+1}\right)^{2}} \ln \frac{2}{q_{1}}$ and $\psi_{q_{1}}=\frac{(k+1) q_{1}^{k} 2^{k}}{2\left(2^{k}-q_{1}^{k+1}\right)^{2}}$ it follows that:

$$
\left(\psi_{k} \frac{k q_{1}^{k-1}}{2^{k}}+\psi_{q_{1}} \frac{q_{1}^{k}}{2^{k}} \ln \frac{2}{q_{1}}\right)=\frac{q_{1}^{2 k}}{2\left(2^{k}-q_{1}^{k+1}\right)^{2}} \ln \frac{2}{q_{1}}>0
$$

Furthermore, using the expression of $\psi\left(k, q_{1}\right)$ I obtain that:

$$
\begin{aligned}
(1+2 \psi) \ln \frac{1+\psi}{\psi}-2 & =\frac{2^{k}}{2^{k}-q_{1}^{k+1}} \ln \left(\frac{\left(2^{k+1}-q_{1}^{k+1}\right)}{q^{k+1}}\right)-2> \\
& >\frac{2^{k}}{2^{k}-1} \ln \left(2^{k+1}-1\right)-2> \\
& >-2+2 \ln 3>0
\end{aligned}
$$

This proves the claim.

Third, I show that social welfare increases as $k$ increases. To see this note that for a given $k$, the social welfare is $S W\left(k, q_{1}, c\right)=\tilde{p}-q_{1} c-\left(1-q_{1}\right) 2 c=\tilde{p}-2 c+q_{1} c$; since when $k$ increases, $q_{1}$ increases then social welfare increases as well.

Finally, I show that the consumer surplus decreases as $k$ increases. To see this note that the consumer surplus is $C S=E u\left(q_{1}=1\right)=E u\left(q_{2}=1\right)=\tilde{p}-E_{\min }(p)-$ $2 c$. Given he price distribution $F\left(p ; k, q_{1}\right)$, the distribution of the minimum price 
is $F_{\min }\left(p ;, k, q_{1}\right)=F\left(p ; k, q_{1}\right)\left(2-F\left(p ;, k, q_{1}\right)\right)$. Using the expression for $F\left(p ; k, q_{1}\right)$ illustrated in proposition 5.3, I obtain $F_{\min }\left(p ;, k, q_{1}\right)=1-\psi^{2}\left(\frac{\tilde{p}-p}{p}\right)^{2}$. Therefore $\frac{\partial F_{\min }\left(p ;, k, q_{1}\right)}{\partial k}<0$ if and only if $\frac{d \psi}{d k}>0$, which follows from above. This completes the proof.

\section{Low Search Intensity Equilibrium}

\section{Proof of Proposition 5.1.}

I first note that for an equilibrium $\bar{p}=\tilde{p}$; for otherwise a firm charging $\bar{p}<\tilde{p}$ strictly gains by increasing such price. Second, note that expressions (7) and (8) can be rewritten as follows

$$
\begin{aligned}
D_{i}\left(k, q_{0}\right) & =\frac{m\left[\left(1+q_{0}\right)^{k+1}-2^{k+1} q_{0}^{k+1}\right]}{2^{k+1}} \\
D_{i, j}\left(k, q_{0}\right) & =\frac{m\left[2^{k}\left(1+q_{0}^{k+1}\right)-\left(1+q_{0}\right)^{k+1}\right]}{2^{k}}
\end{aligned}
$$

Using (16) and (17), expression 9 and the fact that $\bar{p}=\tilde{p}$, it follows that the expected equilibrium profit is $E \pi^{*}=\left(m\left((1+q)^{k+1}-2^{k+1} q^{k+1}\right) / 2^{k+1}\right) \tilde{p}$. In equilibrium it must be the case that $E \pi(p)=E \pi^{*} \forall p \in \sigma$. Solving the equilibrium conditions I obtain the expression for $F(p ; k)$. Similarly, the expression of the lowerbound is the solution of $E \pi(\underline{p})=E \pi^{*}$. Finally, let $\psi\left(k, q_{0}\right)=\frac{\left(1+q_{0}\right)^{k+1}-2^{k+1} q_{0}^{k+1}}{2\left(2^{k}\left(1+q_{0}^{k+1}\right)-\left(1+q_{0}\right)^{k+1}\right)}$; then to prove the first order stochastic dominance relation it is enough to see that $\frac{\partial \psi\left(k, q_{0}\right)}{\partial k}=$ $\frac{\left[2^{k}\left(1-q_{0}^{k+1}\right)\left(1+q_{0}\right)^{k+1}\left(\ln \left(1+q_{0}\right)-\ln 2\right)+2^{k} q_{0}^{k+1}\left(\left(1+q_{0}\right)^{k+1}-2^{k+1} q_{0}^{k+1}\right) \ln \left(q_{0}\right)\right]}{2\left(2^{k}\left(1+q^{(k+1)}\right)-(1+q)^{k+1}\right)^{2}}<0$.

\section{Proof of Theorem 5.1.}

Without loss of generality let $\tilde{p}=1$. Using the expression of the price distribution $F\left(p ; k, q_{0}\right)$ defined in proposition 5.4 , I can invert it to obtain:

$$
p\left(z, k, q_{0}\right)=\frac{1}{g\left(z ; k, q_{0}\right)}
$$

where

$$
g\left(z ; k, q_{0}\right)=1+\frac{2^{k+1}\left(1+q_{0}^{k+1}\right)-2\left(1+q_{0}\right)^{k+1}}{\left(1+q_{0}\right)^{k+1}-2^{k+1} q_{0}^{k+1}}(1-z)
$$

Using (18) the equilibrium condition (12) can be rewritten as follows:

$$
\frac{\left(1+q_{0}\right)^{k}-2^{k+1} q_{0}^{k}}{2^{k}} \int_{0}^{1} p\left(z, k, q_{0}\right)(2 z-1) d z+q_{0}^{k}\left(1-2 \int_{0}^{1} p\left(z, k, q_{0}\right)(1-z) d z\right)=c
$$

I denote as $\rho\left(z ; k, q_{0}\right)$ the LHS of 20 and I note that: 


$$
\begin{aligned}
& \lim _{q_{0} \rightarrow 0} \rho\left(z ; k, q_{0}\right)=\bar{c}(k) \\
& \lim _{q_{0} \rightarrow 1} \rho\left(z ; k, q_{0}\right)=0
\end{aligned}
$$

Furthermore, I note that limit when $q_{0}$ goes to zero of the derivative of $\rho(z, k, q)$ is positive: ${ }^{22}$

$$
\lim _{q_{0} \rightarrow 0} \frac{\partial \rho\left(z ;, k, q_{0}\right)}{\partial q_{0}}=1
$$

Hence, since $\rho\left(q_{0}, k\right)$ is positive at $q_{0}=0$, increasing in the neighbor of $q_{0}=0$ and it is zero at $q_{0}=1$ it follows that for any $k>0$ there exists a $\tilde{c}>\bar{c}(k)$ such that for any $c \in[\bar{c}(k), \tilde{c}]$ There exists at least two solutions of the equilibrium condition (12). It is easy to see that among these two solutions only the smaller one is stable.

I finally show that a consumer does not have an incentive to deviate. The expected utility to a consumer who deviates by searching twice is:

$$
E u^{d}\left(q_{2}=1\right)=\tilde{p}-E_{\min }(p)-2 c
$$

For an equilibrium it must be the case that this deviation is not profitable, i.e. $E u^{d}\left(q_{2}=1\right) \leq E u\left(q_{1}=1\right)$. Using the expression (??) I obtain that $E u^{d}\left(q_{2}=1\right) \leq$ $E u\left(q_{1}=1\right)$ if and only if:

$$
c \geq \frac{\left(1+q_{0}\right)^{k}}{2^{k}}\left[E(p)-E_{\min }(p)\right]
$$

Using the equilibrium condition (12), I can rewrite this inequality as

$$
E(p)-E_{\min }(p) \leq \tilde{p}-E(p)
$$

In the proof of proposition 5.2 I have shown that:

$$
E(p)-E_{\min }(p)=[\tilde{p}-E(p)]-\int_{\underline{p}}^{\tilde{p}}[F(p)]^{2} d p<[\tilde{p}-E(p)]
$$

Hence, given that all consumers randomized between searching once and not searching at all, a consumer does not want to deviate by searching twice. This completes the proof.

\footnotetext{
${ }^{22}$ I develop the result using the program Mathematica. To do this I compute the following transformation. Let $\rho_{q_{0}}\left(q_{0}, k\right)=\frac{\partial \rho\left(q_{0}, k\right)}{q_{0}}$, then $\lim _{q_{0 \rightarrow 0}} \rho_{q_{0}}\left(q_{0}, k\right)=e^{\lim _{q_{0} \rightarrow 0} \ln \left(\rho_{q_{0}}\left(q_{0}, k\right)\right)^{q_{0}}}$. The computation is avaialable upon request of the author.
} 